treatment of tubercular ulcers. The usc of cocaine in laryngeal operations is discussed. Intoxications are rare, and are due to idiosyncrasy. The author favours Voltolini's sponge method for papillomata, which, however, recur after every method of operation. Cy'sts of the vocal cord were seen in two cases, and one was operated upon. Five cases of carcinoma were seen, and two were cured by extirpation of the larynx. Stenoses are treated with Schroctter's tin and hard rubber bougies.

Many cases of laryngeal paralysis were seen, two of aphonia spastica, and one of chorea laryngis. Compression of the trachea was met with in ten cases of struma. Many cases of reflex neuroses of the nose were seen, and local applications, particularly of the galuano-cautery; were most beneficial.

Olena was treated with $\frac{1}{2}$ per cent. salt irrigations, and eczema with diachylon ointment. A frequent cause of epistaxis was noted in enlarged ressels of the septum and excoriations of this locality, and the galvanocautery was the best treatment. Polypi and other growths in the nares were operated on by galvano-cautery, cold wire, or forceps.

A rhinolith was found in one case. Adenoid vegetations were operated on with cutting forceps.

Michael.

\title{
HERING, T.-The Curability of Laryngeal Phthisis by Surgical Methods. A work based on Microscopic, Anatomico-Pathological, and Clinical Observations. IVarsaze, 1887.
}

Tuls is a very careful work, illustrated with many plates, and deals with the etiology and pathological anatomy, and pathological proofs of the curability of phthisical ulcers of the larynx; a description of the surgical methods invented and employed by the author, viz., curetting, frictions, and injections of lactic acid, and injections of iodoform emulsion; a description, with drawings, of the instruments invented by the author; and lastly, the history of thirty-five cases in which these methods were employed. From the author's observations, the conclusions are arrived at, that laryngeal phthisis ought to be treated locally by surgical methods, just as tuberculosis of other organs accessible to surgical manipulations ; that by following these methods cicatrization of ulcers can be procured, and a more or less lasting cure, with disappearance of the sufferings of the patient, and gain in strength. Recurrences, however, occur from time to time, and the cure of these ulcers does not influence the progress of the disease in the lungs. Speaking in general terms, this work is careful, giring conclusions which are not too optimistic, even for an author so enthusiastic of his ideas and methods. Hering's treatment consists in the following :-

I. At the commencement of the disease, parenchymatous injections of iodoform emulsion, or of 10 per cent. to 20 per cent. lactic acid, should be made into the larynx.

2. During the stage of softening and inflammation of the infiltrated parts, deep incisions into the affected parts (epiglottis, posterior wall of the larynx, aryepiglottic ligaments), or extirpation of the affected parts by means of forceps, suillotines, and curettes, should be performed. Aniesthesia should first be obtained by to per cent. solution of cocaine, 
or by injection into the mucous membrane of the affected parts of five to eight drops of Io per cent. cocaine (with the addition of 2 per cent. carbolic acid) by means of the author's syringe. Having extirpated the affected parts with the curette, Hering continues local treatment with iodoform, iodol, or lactic acid: In twenty-eight cases the author has succeeded in obtaining complete cicatrization of tubercular ulcers.

Const. Karwowski.

\section{NOTES.}

A Correction.-Dr. E. F. Ingals desires us to correct a misprint which unfortunately occurred in the report of his article on Intubation (see Vol. I. p. 377). Instead of saying that "all foods should be prohibited except by enemata," it should have been "all fluids." The impression which might apparently be conveyed that two of his three successful cases subsequently died is not what was meant by the abstractor. Dr. Ingals's three successful cases are still living.

The Index to the first volume will be forwarded to all subscribers in the course of a few days. 